\title{
Accounting for the Theory of Planned Behaviour in departure time choice
}

\section{Thorhauge, Mikkel; Haustein, Sonja; Cherchi, Elisabetta}

\section{Published in:}

Transportation Research. Part F: Traffic Psychology and Behaviour

Link to article, DOI:

10.1016/j.trf.2016.01.009

Publication date:

2016

Document Version

Peer reviewed version

Link back to DTU Orbit

Citation (APA):

Thorhauge, M., Haustein, S., \& Cherchi, E. (2016). Accounting for the Theory of Planned Behaviour in departure time choice. Transportation Research. Part F: Traffic Psychology and Behaviour, 38, 94-105.

https://doi.org/10.1016/j.trf.2016.01.009

\section{General rights}

Copyright and moral rights for the publications made accessible in the public portal are retained by the authors and/or other copyright owners and it is a condition of accessing publications that users recognise and abide by the legal requirements associated with these rights.

- Users may download and print one copy of any publication from the public portal for the purpose of private study or research.

- You may not further distribute the material or use it for any profit-making activity or commercial gain

- You may freely distribute the URL identifying the publication in the public portal 
Accounting for the Theory of Planned Behaviour in departure time choice

\section{Mikkel Thorhauge}

Department of Transport, Technical University of Denmark,

Bygningstorvet 116B, 2800 Kgs. Lyngby, Denmark, mt@transport.dtu.dk

\section{Sonja Haustein*}

Department of Transport, Technical University of Denmark,

Bygningstorvet 115, 2800 Kgs. Lyngby, Denmark, sonh@transport.dtu.dk

\section{Elisabetta Cherchi}

Department of Transport, Technical University of Denmark, Bygningstorvet 116B, 2800 Kgs. Lyngby, Denmark, elich@ transport.dtu.dk

*corresponding author 


\begin{abstract}
Motivating people to change their departure time could play a key role in reducing peak-hour congestion, which remains one of the most prevalent transport problems in large urban areas. To achieve this behavioural change, it is necessary to better understand the factors that influence departure time choice. So far departure time choice modelling focussed mainly on objective factors, such as time and costs as main behavioural determinants. In this study, we derived psychological factors based on the Theory of Planned Behaviour, estimated them based on structural equation modelling, and included them into a discrete choice model. The psychological factors were measured based on an online questionnaire addressed to car commuters to the city centre of Copenhagen $(N=286)$. The questionnaire additionally included a travel diary and a stated preference experiment with nine departure time choice scenarios. All psychological factors had a significant effect on departure time choice and could improve the model as compared to a basic discrete choice model without latent constructs. As expected, the effects of the psychological factors were different depending on framework conditions: for people with fixed starting times at work, the intention to arrive at work on time (as estimated by subjective norm, attitude, perceived behavioural control) had the strongest effect; for people with flexible working hours, the attitude towards short travel time was most relevant. Limitations, the inclusion of additional psychological factors and their possible interactions are discussed.
\end{abstract}

\title{
Highlights
}

- Psychological factors for departure time choice were derived from the Theory of Planned Behaviour

- Accounting for the Theory of Planned Behaviour in a discrete choice model improved the estimation

- All included psychological factors had a significant effect on departure time choice

- Intention to arrive on time was more relevant for people with fixed starting times

- Attitude towards short travel time was more relevant for people with flexible starting times

\section{Keywords:}

Departure time

Theory of Planned Behaviour

Hybrid choice model

Attitude

Intention 


\section{Introduction}

Road traffic congestion remains one of the most prevalent transport problems in large urban areas as it decreases the attractiveness and liveability of cities. In addition, the fuel and time wasted in traffic have huge financial consequences as well as negative impacts on public health (e.g. Levy et al., 2010).

Congestion is related to commuting to work and a change of departure time could play a key role in reducing peak-hour congestion. A number of studies have shown that people are more likely to change their departure time to avoid congestion than to change their transport mode (Hendrickson \& Planke, 1984; Hess et al., 2007; Kroes et al., 1996; SACTRA, 1994). The question is, however, how people can be motivated for this behavioural change. To answer this question it is necessary to better understand the psychological factors that influence departure time choice. While this question is of particular importance for both commuting by car and by public transport, the focus of this paper is on car commuting.

So far, departure time choice has mainly been investigated from a microeconomic perspective, considering objective factors, such as travel time, arrival time and travel costs as main behavioural determinants. The basic assumption of this rational choice approach is that individuals make a trade-off between costs, travel time and deviations from their preferred arrival time in such a way that their personal benefit is maximized. Later works also included travel time (un)reliability) accounting for uncertainty about the actual travel time during a journey, i.e. the unexpected delay (Arellana et al., 2012; Börjesson, 2007; 2008; 2009; Ettema et al., 2004; Koster \& Verhoef, 2012; Lam \& Small, 2001; Lizana et al., 2013; Noland \& Small, 1995; 2000; Tseng et al., 2011). This concept, often referred to as travel time variability (TTV), is important because people might rethink their departure time choice under the condition of high travel time variability. The subjective importance of time reliability for transport choices was confirmed in a study based on Qmethodology (Cools et al., 2009).

A few studies approached departure time choice taking into account assumptions of prospect theory (Fujii \& Kitamura, 2004; Senbil \& Kitamura, 2004). These studies point to the importance of the decision frame: Fujii and Kitamura (2004) in particular demonstrated that the choice of more or less risky departure times depends on commuters' working conditions and position. Thereby they indirectly proved the relevance of attitudes, namely the subjective importance of arriving at the preferred arrival time for departure time choice.

An alternative research strategy to the indirect measurement of people's preferences through their choices is the direct measurement of psychological factors that are assumed to influence behaviour by standardised items. The selection of these factors should preferably be based on a theoretical model. This strategy allows for the consideration of factors that go beyond specific preferences.

The theoretical relevance of combining psychological and microeconomic perspective roots to the work of McFadden (2000) and Daniel Kahneman (2003), and has been operationalised by BenAkiva et al. (2002) using the hybrid choice models (HCM). During the past decade there have been several applications of HCM to different fields, including transport, but they have focused only on selected psychological factors, mostly attitudes, and the selection of these factors was not strongly theory-based. To our knowledge the only study that explicitly measured psychological factors in econometric models to explain departure time choice is Arellana (2012). He measured attitude towards being on time and towards changes in trip conditions, but finally did not include them into 
the departure time choice model. In the present paper we investigated potentially relevant psychological factors of departure time choice and included them into a discrete choice model based on stated preference experiments. The selection of the psychological variables was based on the assumptions of the Theory of Planned Behaviour (Ajzen, 1991) as described in the following section. In Section 3, we present our specific hypotheses.

\section{Accounting for the Theory of Planned Behaviour in departure time choice}

The Theory of Planned Behaviour (TPB, Ajzen, 1991) can be regarded "as a social psychological variant of the general rational choice approach" (Bamberg, 2012, p. 222). It is one of the most wellestablished psychological models of individual decision making. According to a meta-analysis of 185 studies it accounts for $27 \%$ and $39 \%$ of the variance in behaviour and intention, respectively (Armitage \& Conner, 2001). In transportation research it has in particular been applied to explain and influence travel mode choice (e.g., Bamberg \& Schmidt, 1998; 2001; 2003; Haustein \& Hunecke, 2007; Heath \& Gifford, 2002) and driving violations (e.g., Cestac et al., 2011; Forward, 2009; Møller \& Haustein, 2014). According to the TPB, the intention to perform a given behaviour indicates people's readiness to perform the behaviour, and it is a direct predictor of behaviour. Intention is influenced by attitude, subjective norm, and perceived behavioural control (PBC). Attitude is the degree to which the performance of the behaviour is positively or negatively valued. Subjective norm is defined as the perceived social pressure to engage or not to engage in the behaviour, while PBC refers to people's perceptions of their ability to perform the behaviour. The latter is assumed to be a direct predictor of both intention and behaviour. The lower the actual control over a given behaviour, the more the influence of intention decreases in favour of PBC. In the context of travel mode choice, research on PBC mainly focused on beliefs related to the built environment (accessibility/transport infrastructure; cf. Bamberg, 2012). Haustein \& Hunecke (2007) introduced the concept of perceived mobility necessities (PMN) to more directly address how the actual living situation (e.g. complex household routines due to children and employment) and resulting perceived travel demands influence car use. While PBC and PMN are correlated, merging them to one latent variable resulted in an unacceptable model fit, which indicates that they should be modelled as separate latent variables. The differentiation between PBC and PMN is expected to be also relevant for departure time choice: beliefs about the transport infrastructure are supposed to make it more or less difficult to arrive at the preferred arrival time, while the personal living situation and related perceptions of flexibility and time pressure are supposed to make people less willing to reschedule their departure time.

Departure time choice is a complex task, which to our knowledge has not yet been explicitly studied in the psychological literature. We suggest departure time choice to be determined by three behavioural intentions that may be in conflict with each other, namely (1) the intention to arrive at the preferred arrival time - or more specifically "on time"; (2) the intention to have short travel times; and (3) the intention to have low travel costs. In line with TPB, we expected all three intentions to be determined by attitude, social norm and perceived behaviour control as shown in Figure 1. In addition, we expect PMN to have a direct impact on departure time choice. Including indicators for all these psychological variables was not possible in the design of the present study, so we had to choose those variables that we expected to have the highest added value when included into a discrete choice model. 
The relevance of the attitude towards arriving on time for departure time choice was indirectly confirmed by Fujii and Kitamura (2004). They showed that people in a higher work-place hierarchy (as approximated by age) chose riskier departure time alternatives than people lower in hierarchy. This was assumed because of the different consequences of being late and thus the importance of being on time for both commuter groups, which refers to attitude. Similarly, we assume that the riskier choices are related to less perceived social pressure to arrive on time (subjective norm (SN)) and expect both factors, attitude and SN, to be highly related. We further assume that the intention to arrive at work on time is more relevant for people with fixed working hours than for people under flextime conditions, which is also in line with the finding of Fujii and Kitamura (2004) who showed that people under flextime conditions choose riskier departure time alternatives.

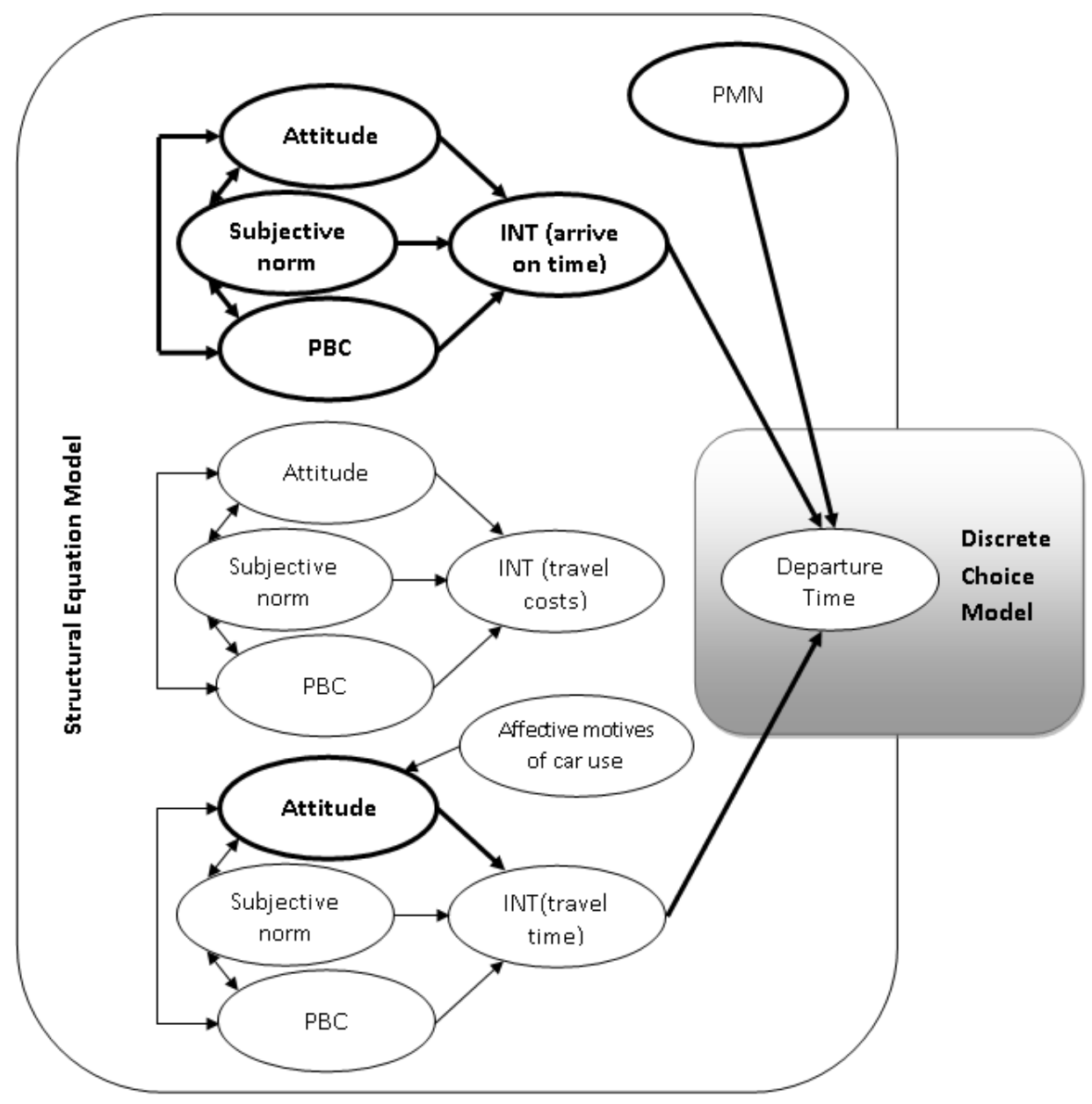

Figure 1: Selection of psychological constructs to be included in the discrete choice model (selected constructs and effects in bold)

With regard to minimizing travel time, we only included the attitude towards short travel time. It has been shown that travelling does not only serve the utility of arriving at the desired destination but also the utility of doing other activities while travelling (e.g. relaxing, thinking, transition between home and work) and also has an intrinsic utility (Mokhtarian \& Salomon, 2001). Thus, people most probably differ with respect to the importance they allocate to short travel times, depending, for example, on how much they like or dislike car driving or queuing. People who associate driving with symbolic and affective motives such as freedom, autonomy and passion 
might be more willing to accept longer travel times by car - and probably rather change their route than their departure time, while people who perceive driving as boring or stressful might find it more important to reduce travel time. These assumptions are supported by empirical results from Beirao and Cabral (2007) who on the one hand identified car users who appreciate the autonomy and flexibility of the car and "feel that they can change route and avoid traffic" (p. 484) and on the other hand captive car users who are nervous or worried about traffic jams and would prefer to use public transport, which would allow them to relax or make use of their time in a different way (p. 482). Subjective norm appears less relevant for minimizing travel time than for arriving on time, also because travel time is not directly observable by others. An exception might be the perceived social pressure of the partner in case of high family demands. Perceived control and intention are probably important, but may be partly captured by Perceived Mobility Necessities (PMN): People who perceive a high pressure to be mobile all the time, most probably intend to have short travel times but are at the same time more likely to be restricted in their possibilities of rescheduling their departure time.

Psychological factors related to minimizing travel costs were not considered. While instrumental motives (Jakobsson, 2007), in particular convenience and costs, are evaluated as important attributes of commuting trips (Anable \& Gatersleben, 2005) they are found to be less useful to explain differences in car use as compared to affective and symbolic motives (e.g., Lois \& LopezSaez, 2009; Steg, 2005). Similarly, we expect that the great majority of commuters would agree that it is important to have low travel costs, which would, however, not contribute much to the explanation of individual differences in departure time choice. To capture the effect of travel costs we think that the indirect measure through the choice in the experimental setting is the preferable method.

\section{Hypotheses}

Several studies, mainly in the transport field, have incorporated latent variables to better explain the discrete choice by capturing psychological constructs. However, none of them explored the effect of the full TPB and none of them studied the effect on departure time choice.

Our main goal was to examine if the TPB is a useful model in the context of departure time choice and to which extent departure time is affected by psychological factors versus microeconomic evaluation of the characteristics of the alternatives. More specifically, we expected the intention to arrive at work on time, as predicted by subjective norm (SN), attitude, and perceived behavioural control (PBC), to have a significant impact on departure time choice as measured in the setting of a stated preference experiment. In addition, we expected perceived mobility necessities (PMN) as well as the attitude towards short travel time to have a significant direct effect on departure time choice.

Based on structural equation modelling (SEM) we first estimated the value of each psychological construct based on its indicators, as well as the intention to arrive at work on time by its predictors: attitude, SN, and PBC.

In a second step, intention and the other psychological variables were included in a discrete choice model (DCM) to test the following specific hypotheses: 
(1) Accounting for the TPB in a sequential approach significantly improves the model estimation as compared to a basic DCM without latent variables.

(2) Accounting for the TPB significantly improves the model estimation as compared to a DCM including intention estimated solely by its own indicator variables.

(3) The inclusion of attitudes regarding travel time and PMN further improves DCM.

(4) Intention to arrive at work on time is more relevant for people with fixed working hours than for people benefitting from flexible time conditions.

\section{Material and method}

\subsection{Questionnaire}

A web-based questionnaire targeted at car commuters was constructed to collect the following information: (1) travel behaviour, including detailed information about the trips and activities performed by each respondent during his/her latest working day, (2) stated preference data, which allowed us to estimate respondents' preferences for departure time and for travel time, cost, and delay (i.e. level of service characteristics), (3) a set of psychological variables to estimate the constructs in relation to the TPB and (4) a set of background variables such as age, sex, income, location, household position and more importantly flexibility about the start/end of the working hours.

In the Stated Preference (SP) experiment different hypothetical but realistic scenarios were presented and respondents were asked to choose their preferred option in each scenario. Each scenario consisted of three possible departure times: the current departure time (i.e. the same as described in the daily trip part of the questionnaire), an earlier and a later departure time. Each scenario was described by four characteristics: departure time (DT), travel cost (TC), travel time (TT), and travel time variability (TTV). A total of 9 scenarios were presented to each respondent, where the values of the characteristics were varied according to specific rules that allow maximising the information about individual preferences that we can infer from the individuals' choices. Figure 2 shows an example of one scenario presented to respondents. More details on how the SP experiment was built can be found in Thorhauge et al. (2014).

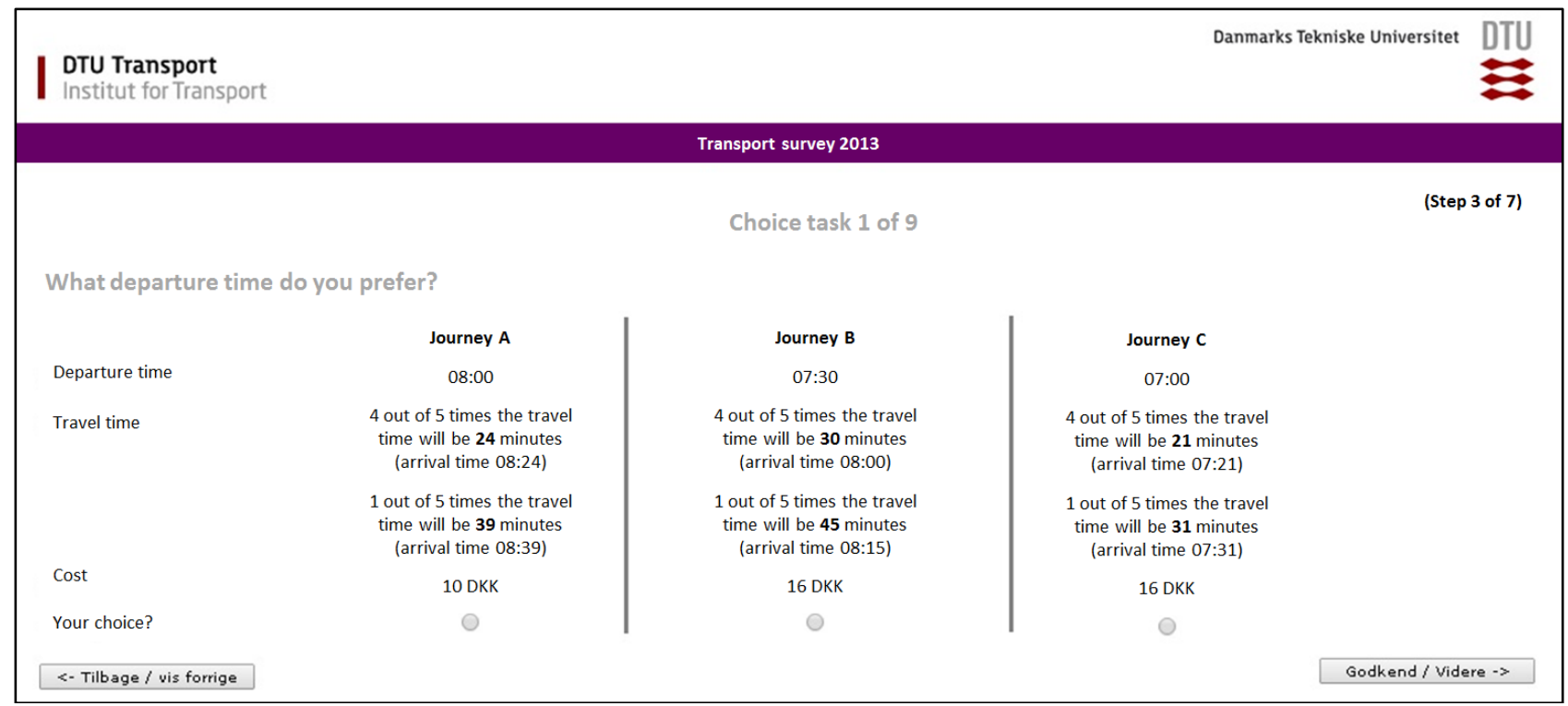

Figure 2: Example of a choice task for a respondent with preferred arrival time 8:00 
Regarding the psychological variables, we included the constructs of the TPB (ATT_late, SN, PBC, INT), as well as perceived mobility necessities (PMN) and the attitude towards short travel time (ATT_time) as explained in Section 2. Each psychological construct was measured by three items on a five-point Likert scale $(1=$ strongly disagree; $5=$ strongly agree). Table 1 lists the items including their means and standard deviations as well as the internal consistencies of the psychological constructs. Most internal consistencies lie between .9 and .8 and can thus be described as good, whereas PBC and ATT_time with values between .7 and .6 are just acceptable. In both cases (PBC and ATT_time), deleting one item would further decrease the internal consistency. Thus, rather than replacing existing items, we recommend an extension of the number of items to measure these latent variables.

Table 1: Psychological constructs and their indicators

\begin{tabular}{|c|c|c|c|c|c|}
\hline \multicolumn{2}{|c|}{ Latent variables } & Indicators & $M$ & $S D$ & Cronbach's $\alpha$ \\
\hline \multicolumn{6}{|l|}{ TPB } \\
\hline \multirow{3}{*}{$\begin{array}{l}\text { Attitude } \\
\text { towards } \\
\text { being late }\end{array}$} & ATT_late_1 & It is very important for me to be at work on time. & 4.06 & 1.14 & \multirow{3}{*}{.85} \\
\hline & ATT_late_2 & Coming too late to work is very unpleasant for me. & 3.73 & 1.29 & \\
\hline & ATT_late_3 & It is problematic for me to be late for work. & 3.63 & 1.35 & \\
\hline \multirow{3}{*}{$\begin{array}{c}\text { Subjective } \\
\text { norm }\end{array}$} & SN_1 & My colleagues think that I should be at work on time. & 3.31 & 1.41 & \multirow{3}{*}{.86} \\
\hline & SN_2 & My boss thinks that I should be at work on time. & 3.35 & 1.45 & \\
\hline & $\mathrm{SN} \_3$ & People, who are important to me, think I should be at work on time. & 3.27 & 1.35 & \\
\hline \multirow{3}{*}{$\begin{array}{c}\text { Perceived } \\
\text { behavioural } \\
\text { control }\end{array}$} & PBC_1 & It is easy for me to be at work on time. & 4.18 & 0.96 & \multirow{3}{*}{.65} \\
\hline & PBC_2 & It is difficult for me to be at work on time. ${ }^{a}$ & 4.57 & 0.75 & \\
\hline & $\mathrm{PBC}_{-} 3$ & It is possible for me to be at work on time if I want to. & 4.22 & 1.08 & \\
\hline \multirow{3}{*}{ Intention } & INT_1 & I intend to be at work on time in the near future. & 4.38 & 0.92 & \multirow{3}{*}{.81} \\
\hline & INT_2 & I intend to avoid delays in arrival time at work in the near future. & 3.92 & 1.15 & \\
\hline & INT_3 & I plan to be at work on time in the near future. & 4.31 & 0.97 & \\
\hline \multicolumn{6}{|c|}{ Additional latent variables } \\
\hline \multirow{3}{*}{$\begin{array}{c}\text { Attitude } \\
\text { towards } \\
\text { short travel } \\
\text { time }\end{array}$} & ATT_time_1 & It is very important for me to have short TT to/from work. & 3.77 & 1.12 & \multirow{3}{*}{.67} \\
\hline & ATT_time_2 & Having a long TT to/from work is very stressful for me. & 3.53 & 1.22 & \\
\hline & ATT_time_3 & I don't care about long TT to my work. ${ }^{1}$ & 4.35 & 0.95 & \\
\hline \multirow{3}{*}{$\begin{array}{l}\text { Perceived } \\
\text { mobility } \\
\text { necessities }\end{array}$} & PMN_1 & The organization of my everyday life requires a high level of mobility. & 3.40 & 1.25 & \multirow{3}{*}{.83} \\
\hline & PMN_2 & I have to be mobile all the time to meet my obligations. & 3.16 & 1.29 & \\
\hline & PMN_3 & My work requires a high level of mobility. & 2.94 & 1.28 & \\
\hline
\end{tabular}

Notes: All indicator statements were measured based on a 5-point Likert scale $(1=$ strongly disagree; $5=$ strongly agree).

${ }^{\mathrm{a}}$ Item has been re-coded.

\subsection{Procedure and participants}

The target population of this study were 18-65 years old car commuters who worked in the city of Copenhagen. An additional criterion was that individuals had travelled to work in the morning peak period and experienced congestion or queuing on the way to work, as this would prove a vital incentive to reschedule (or at least rethink) their departure time. 
The data was collected contacting individuals directly at their work place. Two universities and three of the biggest companies and public organisations in Copenhagen were selected. For all individuals employed at universities, email addresses were publically available on the webpage of the universities, so that they could be contacted directly. For the individuals working in the companies we contacted a manager in each company and asked for permission to get access to email lists of the employees. All types of employees were included in the sample. More than 10,000 invitations were distributed via email resulting in 923 fully completed questionnaires. 286 of these fulfilled the criteria of the target population as specified above.

Table 2 summarises the main characteristics of our sample $(N=286)$. Demographics and travel and workplace characteristics were compared with data from the Danish National Travel Survey (TU, Christiansen, 2012). For the comparison we only included people living in the Greater Copenhagen Area who commuted by car between 6-10 a.m. As can be seen, our sample differs significantly from the TU sub-sample in many categories. This was to be expected because of the choice to recruit our sample specifically in the academia where people typically have flexible working hours, a higher education level and a higher amount of working hours.

Table 2: Descriptive statistics of the sample and comparison with TU survey

\begin{tabular}{|c|c|c|c|c|c|}
\hline & & $\begin{array}{l}\text { Sample } \\
(N=286)\end{array}$ & $\begin{array}{c}\text { Danish National } \\
\text { Travel Survey } \\
(N=4410)\end{array}$ & $\begin{array}{c}\text { Difference } \\
\mathrm{X}^{2} \\
\end{array}$ & $\begin{array}{c}\text { n samples } \\
p\end{array}$ \\
\hline Gender & $\begin{array}{l}\text { Male } \\
\text { Female }\end{array}$ & $\begin{array}{l}50.3 \% \\
49.7 \% \\
\end{array}$ & $\begin{array}{l}55.9 \% \\
44.1 \% \\
\end{array}$ & 3.34 & .188 \\
\hline Age & $\begin{array}{l}18-29 \\
30-39 \\
40-49 \\
50-59 \\
60+ \\
\end{array}$ & $\begin{array}{c}3.1 \% \\
22.7 \% \\
30.4 \% \\
28.0 \% \\
15.7 \% \\
\end{array}$ & $\begin{array}{c}6.7 \% \\
22.7 \% \\
34.0 \% \\
26.4 \% \\
10.1 \% \\
\end{array}$ & 14.60 & .067 \\
\hline Household type & $\begin{array}{l}\text { Single } \\
\text { Single with child/children } \\
\text { Couple } \\
\text { Couple with child/children }\end{array}$ & $\begin{array}{c}11.5 \% \\
5.2 \% \\
29.0 \% \\
54.2 \%\end{array}$ & $\begin{array}{c}11.9 \% \\
4.1 \% \\
30.8 \% \\
53.1 \%\end{array}$ & 1.27 & .996 \\
\hline Education & $\begin{array}{l}\text { Elementary } \\
\text { High school } \\
\text { University } \\
\text { Other/unknown } \\
\end{array}$ & $\begin{array}{c}0.3 \% \\
1.0 \% \\
93.4 \% \\
5.2 \% \\
\end{array}$ & $\begin{array}{r}5.9 \% \\
7.9 \% \\
58.5 \% \\
27.8 \% \\
\end{array}$ & 137.11 & $<.001$ \\
\hline Work flexibility & $\begin{array}{l}\text { Fixed start/end work time, } \\
\text { Flexible start/end work time } \\
\text { Unemployed/unknown }\end{array}$ & $\begin{array}{c}33.6 \% \\
65.0 \% \\
1.4 \% \\
\end{array}$ & $\begin{array}{l}36.4 \% \\
22.6 \% \\
40.9 \% \\
\end{array}$ & 301.11 & $<.001$ \\
\hline $\begin{array}{l}\text { Work hours } \\
\text { per week }^{\mathrm{a}}\end{array}$ & $\begin{array}{l}\text { Less than } 37 \text { hours } \\
37 \text { hours } \\
\text { More than } 37 \text { hours }\end{array}$ & $\begin{array}{c}8.4 \% \\
29.4 \% \\
62.2 \% \\
\end{array}$ & $\begin{array}{l}16.6 \% \\
49.1 \% \\
34.2 \% \\
\end{array}$ & 91.93 & $<.001$ \\
\hline $\begin{array}{l}\text { Individual income } \\
{[1000 \mathrm{DKK}]}\end{array}$ & $\begin{array}{l}\text { Low }(<300) \\
\text { Medium }(300-600) \\
\text { High }(>600) \\
\text { Unknown }\end{array}$ & $\begin{array}{l}4.5 \% \\
49.7 \% \\
36.4 \% \\
8.7 \% \\
\end{array}$ & $\begin{array}{c}12.9 \% \\
53.4 \% \\
18.3 \% \\
6.9 \% \\
\end{array}$ & 62.10 & $<.001$ \\
\hline $\begin{array}{l}\text { Commuting } \\
\text { distance }[\mathrm{km}]\end{array}$ & $\begin{array}{l}1-10 \\
11-20 \\
21-30 \\
31-40 \\
41-50 \\
\text { More than } 50 \\
\text { Mean (std. dev) }\end{array}$ & $\begin{array}{c}25.2 \% \\
30.4 \% \\
20.6 \% \\
13.6 \% \\
9.4 \% \\
0.7 \% \\
21.2(12.9) \\
\end{array}$ & $\begin{array}{c}33.0 \% \\
27.6 \% \\
17.3 \% \\
10.9 \% \\
5.5 \% \\
5.7 \% \\
22.1(24.4) \\
\end{array}$ & 29.05 & $<.01$ \\
\hline
\end{tabular}

37 hours is the norm for a standard working week in Denmark. The number of working hours includes the total working hours per week regardless of whether the work is conducted from the work place or another location, e.g. home). 
Table 2 also compares the distance travelled and the travel time between our sample and the TU sub-sample. In our sample short trips (=less than $10 \mathrm{~km}$ ) and long distance trips (=more than $50 \mathrm{~km})$ are underrepresented. Finally, it is also interesting to note that $68 \%$ of the individuals in our sample commute by car to work on a daily basis, $26 \%$ several times a week, and only $6 \%$ on a weekly basis or less, which provides an indication of the extent to which the trip is habitualized. Unfortunately, this information is not available in TU data.

The sample consists of 286 individuals, each presented with 9 SP choice tasks. After a cleaning of the survey, 2515 observations were used for estimation.

\section{Models and results}

In this section we first describe the results of the structural equation model (SEM), and then the integration of the TPB and additional psychological factors into the discrete choice models (DCM).

\subsection{Intention to arrive at work on time}

We estimated the latent variables for each of the latent construct, as well as the full Theory of Planned Behaviour (TPB) for the intention to arrive at work on time. Figure 3 shows the results of the SEM, in which intention is predicted by attitude, subjective norm, and perceived behavioural control in line with the assumptions of the TPB. The latent constructs were measured by the indicator items described in Table 1. The model was estimated using SPSS AMOS Version 22.

While all predictors of intention were statistically significant $(p<.001)$, a positive attitude towards being at work on time had by far the strongest effect on intention $(\beta=.61)$. The social pressure to arrive on time, as captured by subjective norm, and perceiving it easy to arrive on time, had similar but lower effects $(\beta=.23 ; \beta=.24)$. As expected, attitude and subjective norm were strongly correlated $(\mathrm{r}=.52 ; p<.001)$, while the correlations with PBC were not significant $(p>.10)$.

The model's fit statistics are provided in the legend of Figure 1. Hu and Bentler (1999) suggest a two-index presentation strategy to evaluate model fit. Among others, CFI $>.95$ in combination with SRMR $<.09$ are recommended, especially for small sample sizes $(N<=250)$, to conclude that the model fits the observed data well, which is the case in our example. Intention as estimated in the model was included in the DCM as described below. 


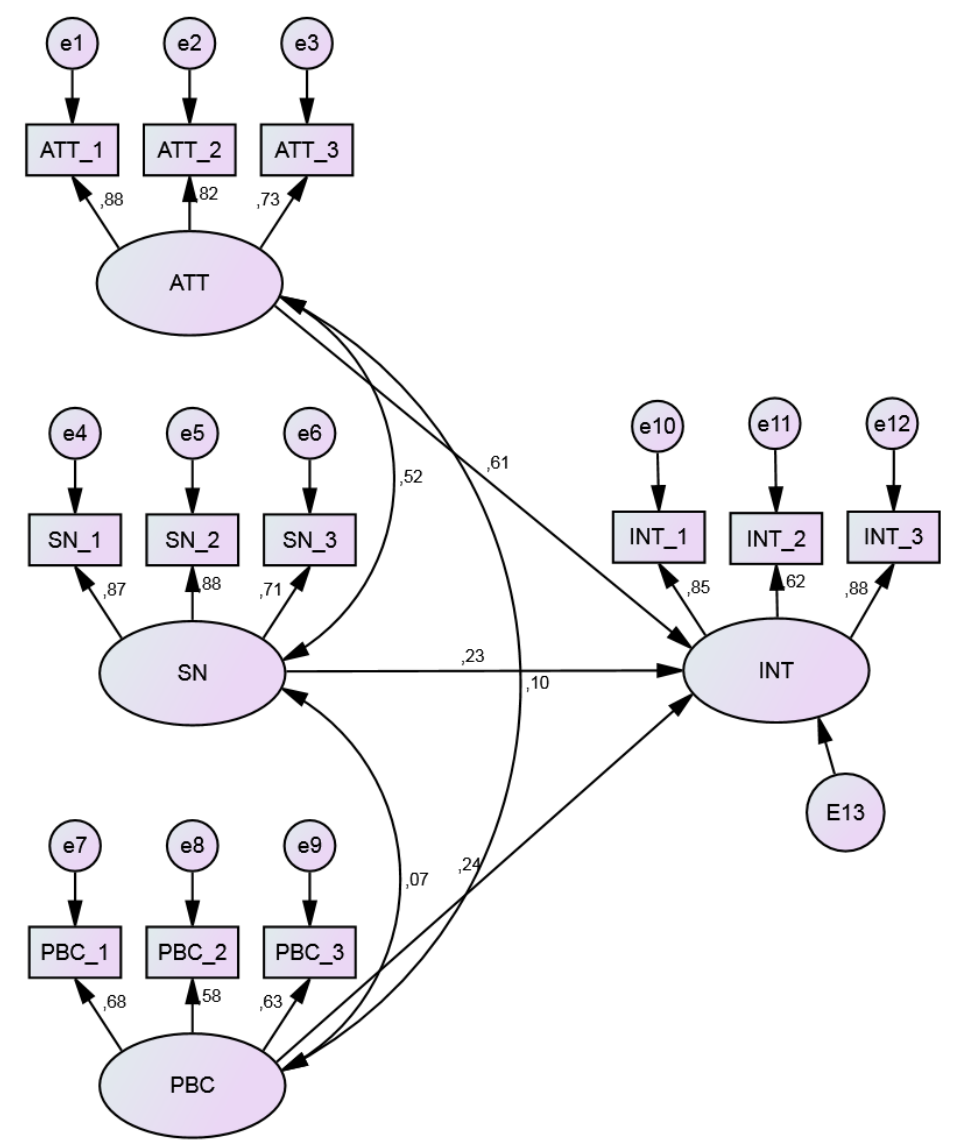

Figure 3: Intention to arrive at work on time Notes: $N=286 ;$ Fit statistics: $\mathrm{CFI}=.952 ; \mathrm{RMSEA}=.074 ; \mathrm{SRMR}=.0523 ; \mathrm{Chi} 2=123.89, \mathrm{df}=48$

\subsection{Integrating TPB in the departure time choice}

The microeconomic approach to departure time choice is based on the concept that individuals make a trade-off between travel time and penalties for rescheduling, i.e. being early or late. For that we rely on the scheduling model (Small, 1982) that assumes that travellers $(n)$ choose the alternative $(j)$ that gives them the highest utility $(U)$, defined as a linear combination of attributes describing the alternatives. In the latest version of the scheduling model the discrete choice among departure time alternatives is expressed as a function of travel cost $(T C)$; the expected travel time $(E(T T))$ from origin to destination weighted by the probability of experiencing additional (unforeseen) travel time; the weighted expected scheduled delay early $(E(S D E))$ and late $(E(S D L))$, i.e. the difference between the individual preferred arrival time and the actual arrival time, and an extra penalty for being late $(D L)$.

The typical scheduling model (SM) assumes that individual preferences are affected only by attributes that measure the level-of-service (LOS). We extended the SM to account for the fact that individual preferences can be (and typically are) also affected by latent effects, such as attitudes and intentions. The extended SM takes the following form:

$U_{j n t}=A S C_{j}+\beta_{T T} E\left(T T_{j n t}\right)+\beta_{T C} T C_{j n t}+\beta_{S D E} E\left(S D E_{j n t}\right)+\beta_{S D L} E\left(S D L_{j n t}\right)+\beta_{D L} D L_{j n t}+\boldsymbol{\beta}_{L V} \boldsymbol{L} \boldsymbol{V}_{\boldsymbol{n}}+\mu_{j n}+\varepsilon_{j n t}$ 
Where $L V_{n}$ is a vector of latent variables for individual $n$ estimated in the structural equation model (SEM), ASC is a vector of constants specific for each alternative $j, \varepsilon_{j n t}$, is an error term distributed identically and independently extreme value type 1 , while $\mu_{j n}$ is a normally distributed error component that captures the correlation among choice tasks $(t)$ answered by the same individual. All the other attributes have the meaning explained above and the $\beta_{s}$ are the parameters, associated to each attribute, to be estimated.

The model in the equation (1) is called a hybrid choice model (Ben-Akiva et al., 1999; Walker, 2001), because it integrates the typical discrete choice model (namely the SM) with the structural equation model (for the LV). In this paper, we used a sequential estimation, which is a two-step process. First the latent variables (i.e. intention with regard to being late, PMN, and attitude with regard to having short travel times) were estimated based on SEM and afterward included in the discrete choice model (DCM) as explanatory variables.

The sequential estimation is used when the hybrid choice models are particularly complex (as in our case) and hence difficult to converge and to be empirically identified. The sequential estimation however can result in potentially biased estimators, which are not guaranteed to be consistent, and can underestimate the standard deviation of the parameters. According to Yanez et al. (2010) the problem with biased estimates can be solved by adding a random term to the LVs. However, empirical tests conducted by Raveaux et al. (2010) using real and synthetic data showed that (albeit only for the MNL model) both sequential and simultaneous estimation methods are unbiased and that the difference does not affect the model estimates significantly. Due to the complex set of latent constructs used in this study, the straightforward approach of the sequential estimation was highly desirable.

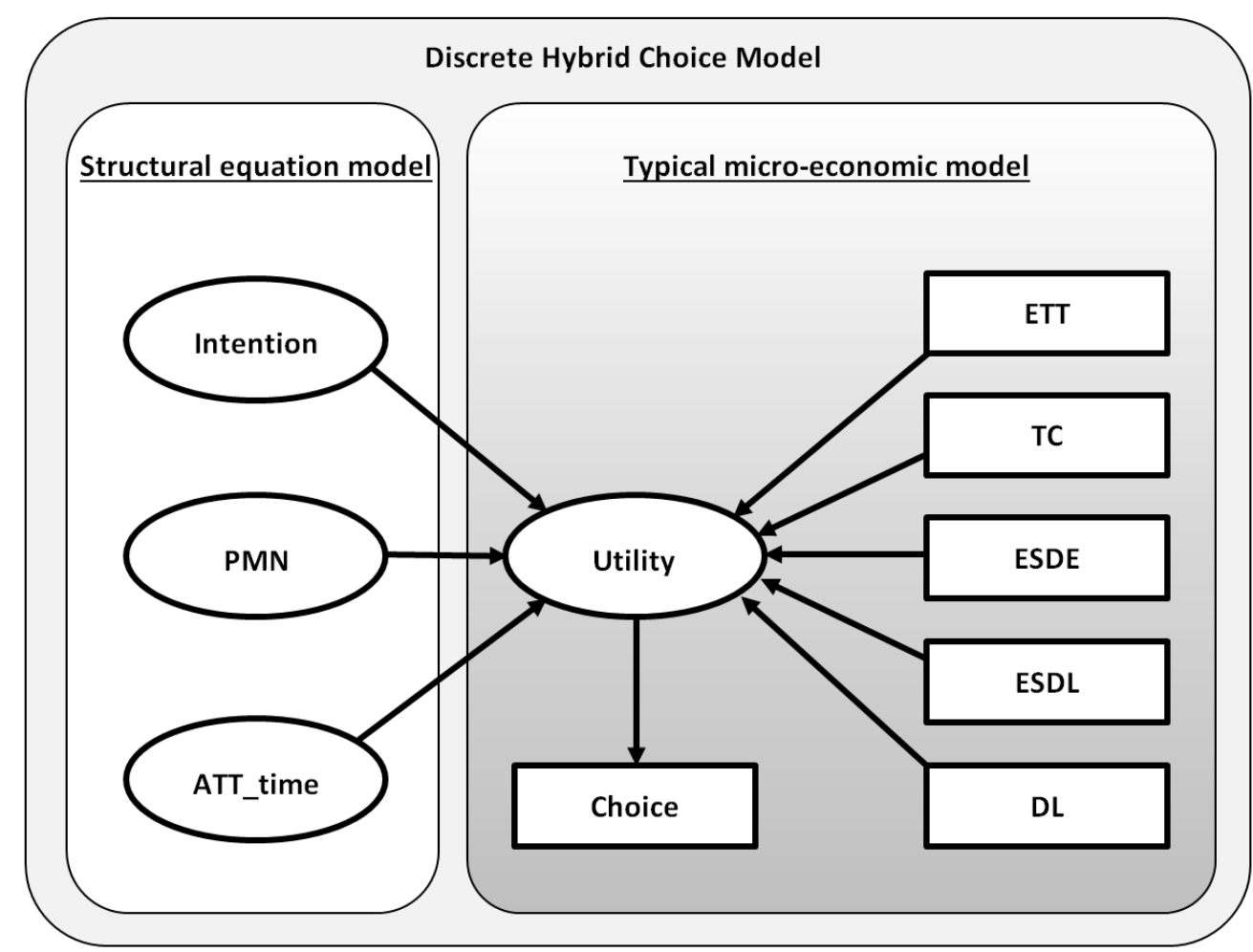

Figure 4: Incorporating latent variables into the micro-economic discrete choice framework 
Table 3 shows the results of the model estimated. For purposes of comparison we first estimated the basic scheduling model alone, without any latent effects. The remaining models in Table 3 are hybrid choice models, accounting explicitly for latent effects as justified by the Theory of Planned Behaviour. All models account for panel correlation among the stated preference observations answered by the same individual $n$, following the specification in Walker et al. (2007). The models were estimated using PythonBiogeme (Bierlaire, 2003; Bierlaire \& Fetiarison, 2009).

As expected, all coefficients in the scheduling model part were negative and significant $(p<.001)$. The negative sign was as expected, as it indicates that utility decreases if any one of the attributes increases. In other words, if an attribute increases (e.g. travel time or scheduling delay) the probability of selecting that departure time option decreases. Thus, (perfectly rational) individuals seek to balance the attributes by choosing the departure time that gives them the highest overall utility (i.e. lowest disutility). The most important attribute for the respondents in our sample was travel time, while the scheduling penalties was the least important as indicated by the marginal utility of $\mathrm{E}(T T)$ being higher than both $\mathrm{E}(S D E)$ and $\mathrm{E}(S D L)$. This can be explained by the fact that $65 \%$ of the respondents had flexible working start times, so that their exact arrival time is probably less important. Respondents whose main priority is travel time are likely to select either the early or the late departure option to lower their travel time.

The latent variables part shows the direct influence of the psychological factors in the choice of departure time. HCM1 includes intention as a separate variable, explained solely by its three indicator items (see Table 1). By contrast, HCM2 includes intention as explained by a set of lower level latent variables, ATT_late, SN, and PBC. Both models only include the LV in the alternative of being late, as the parameter for early departure was not significant in the other alternatives, and was thus removed. As expected the parameters were negative. This means that individuals who intend to be at work on time gain disutility of being late, but since the parameter was not significant for early departure, it means that they are indifferent if they arrive early or arrive on time. We estimated specific parameters for individuals with fixed working hours and flexible working hours, and as expected the penalty of late arrival is much more prevalent for individuals with fixed arrival. Comparing intention in HCM1 and HCM2 we found that the value of the LV is slightly higher and more significant when intention is explained by ATT_late, SN, and PBC (as in model HCM2) than when it is explained only by its indicators (as in model HCM1). In addition, the parameters in the SM were almost identical, hence the intention estimated based on the TPB better captured the behaviour than intention alone.

In HCM3 we added perceived mobility necessities (PMN) and attitude towards short travel time (ATT_time) as additional latent constructs to intention (based on the TPB) to further increase the explanatory power of the model. We found that PMN were significant for the late departure. On the other hand ATT_time was significant for both early and late departures for individuals with flexible working hours, while not statistically significant $(p<.05)$ for individuals with fixed working hours. This makes sense as individuals with flexible working hours are mainly concerned about being at work on time. All LVs have the expected sign: PMN is negative for late arrival, since individuals who have high perceived mobility needs are less likely to have room to reschedule. Similarly, ATT_time was positive, since individuals who find it important to have short travel times are more likely to reschedule their departure time in order to reduce travel time. It is also interesting how differently the LVs affect individuals with flexible and fixed working hours: ATT_Time and PMN are more important for individuals who have flexible working hours, while intention to be at work 
on time is more important for individuals with fixed working hours, which is in line with our Hypothesis 4.

Table 3: Results of the DCM

\begin{tabular}{|c|c|c|c|c|c|c|c|c|c|c|c|c|}
\hline \multirow{2}{*}{$\begin{array}{l}\text { Model } \\
\text { Scheduling model }\end{array}$} & \multicolumn{3}{|c|}{ Scheduling model } & \multicolumn{3}{|c|}{ HCM1 } & \multicolumn{3}{|c|}{ HCM2 } & \multicolumn{3}{|c|}{ HCM3 } \\
\hline & Values & $t$-test & & values & $t$-test & & values & $t$-test & & values & $t$-test & \\
\hline ASC (Early Dep) & -1.470 & $(-3.68)$ & $* * *$ & -1.440 & $(-3.61)$ & $* * *$ & -1.440 & $(-3.61)$ & $* * *$ & -2.310 & $(-2.62)$ & $* *$ \\
\hline ASC (Late Dep) & -0.604 & $(-1.64)$ & & 1.170 & $(1.67)$ & & 1.480 & $(2.06)$ & $*$ & 0.631 & $(0.70)$ & \\
\hline$\beta_{\text {ETT }}$ & -0.205 & $(-8.88)$ & $* * *$ & -0.202 & $(-8.78)$ & $* * *$ & -0.202 & $(-8.80)$ & $* * *$ & -0.204 & $(-8.88)$ & $* * *$ \\
\hline$\beta_{\mathrm{TC}}$ & -0.156 & $(-9.28)$ & $* * *$ & -0.154 & $(-9.20)$ & $* * *$ & -0.154 & $(-9.21)$ & $* * *$ & -0.155 & $(-9.22)$ & $* * *$ \\
\hline$\beta_{\mathrm{ESDE}}$ & -0.037 & $(-4.64)$ & $* * *$ & -0.038 & $(-4.72)$ & $* * *$ & -0.038 & $(-4.72)$ & $* * *$ & -0.037 & $(-4.66)$ & $* * *$ \\
\hline$\beta_{\mathrm{ESDL}}$ & -0.088 & $(-9.17)$ & $* * *$ & -0.088 & $(-9.12)$ & $* * *$ & -0.088 & $(-9.14)$ & $* * *$ & -0.089 & $(-9.32)$ & $* * *$ \\
\hline$\beta_{\mathrm{DL}}$ & -0.394 & $(-2.56)$ & $*$ & -0.384 & $(-2.51)$ & $*$ & -0.384 & $(-2.51)$ & $*$ & -0.381 & $(-2.48)$ & $*$ \\
\hline St.dev (Early Dep) & -2.200 & $(-12.42)$ & $* * *$ & -2.220 & $(-12.30)$ & $* * *$ & -2.220 & $(-12.31)$ & $* * *$ & -2.190 & $(-12.56)$ & $* * *$ \\
\hline St.dev (Late Dep) & -2.860 & $(-13.77)$ & $* * *$ & -2.590 & $(-12.38)$ & $* * *$ & -2.570 & $(-12.36)$ & $* * *$ & -2.480 & $(-12.94)$ & $* * *$ \\
\hline Corr (Early-Late) & -1.600 & $(-6.32)$ & $* * *$ & -1.510 & $(-5.01)$ & $* * *$ & -1.510 & $(-5.04)$ & $* * *$ & -1.410 & $(-5.39)$ & $* * *$ \\
\hline \multicolumn{13}{|c|}{ Latent variables Fixed working hours } \\
\hline$\beta_{\text {LV_ATT_time }}($ Early Dep) & & & & & & & & & & 0.047 & $(0.17)$ & \\
\hline$\beta_{\text {LV_ATT_time }}($ Late Dep) & & & & & & & & & & 0.320 & $(0.87)$ & \\
\hline$\beta_{\text {LV_INT }}($ Late Dep $)$ & & & & -0.683 & $(-4.28)$ & $* * *$ & -0.765 & $(-4.60)$ & $* * *$ & -0.765 & $(-2.59)$ & $* *$ \\
\hline$\beta_{\text {LV_PMN }}($ Late Dep $)$ & & & & & & & & & & -0.160 & $(-0.65)$ & \\
\hline \multicolumn{13}{|c|}{ Latent variables Flexible working hours } \\
\hline$\beta_{\text {LV_ATT_time }}($ Early Dep) & & & & & & & & & & 0.451 & $(1.61)$ & \\
\hline$\beta_{\text {LV__ATT_time }}($ Late Dep) & & & & & & & & & & 0.817 & $(2.70)$ & $* *$ \\
\hline$\beta_{\text {LV_INT }}($ Late Dep) & & & & -0.322 & $(-2.07)$ & $*$ & -0.416 & $(-2.49)$ & * & -0.425 & $(-2.14)$ & $*$ \\
\hline$\beta_{\text {LV_PMN }}($ Late Dep $)$ & & & & & & & & & & -0.445 & $(-2.55)$ & $*$ \\
\hline \multicolumn{13}{|l|}{ Summary } \\
\hline Sample size: & & 2515 & & & 2515 & & & 2515 & & & 2515 & \\
\hline Number of draws: & & 1000 & & & 1000 & & & 1000 & & & 1000 & \\
\hline Null log-likelihood: & & 2763.01 & & & -2763.01 & & & 2763.01 & & & 2763.01 & \\
\hline Final log-likelihood: & & 791.042 & & & 1774.349 & & & 773.171 & & & 762.385 & \\
\hline $\mathrm{RHO}^{2}$ for the null model: & & 0.352 & & & 0.358 & & & 0.358 & & & 0.362 & \\
\hline $\begin{array}{l}\text { Adjusted } \mathrm{RHO}^{2} \text { for the } \\
\text { null model: }\end{array}$ & & 0.348 & & & 0.353 & & & 0.354 & & & 0.356 & \\
\hline
\end{tabular}

Notes: Numbers in brackets represent the $t$-test statistics. $* p<.05 ; * * p<.01 ; * * * p<.001$.

To test Hypotheses 1-3, we performed a likelihood ratio test (Ben-Akiva \& Lerman, 1985) for all models against the basic SM and found that the model fit for all three models significantly improved $(p<.01)$. Similarly, we compared the likelihood ratio test between model HCM2 and HCM3, and found that model HCM3 was also significantly better $(p<.01)$. The likelihood ratio test can however only be used to compare nested models, hence we could not compare HCM1 with HCM2 and HCM3. However, comparing the adjusted $\mathrm{RHO}^{2}$ values we saw that HCM3 was better than both HCM1 and HCM2. Thus, the results support our hypotheses.

\section{Discussion and conclusions}

In this paper, we have shown that the understanding and modelling of departure time choice can be improved by the inclusion of relevant psychological factors into a DCM. For the selection of psychological factors we relied on the assumptions of the Theory of Planned Behaviour (TPB). We assumed three behavioural intentions to play a role for departure time choice: the intention to arrive on time; the intention to have short travel times; and the intention to have low travel costs. With regard to the intention to arrive at work on time, we estimated intention as determined by subjective norm, attitude, and PBC by structural equation modelling. When comparing the results of the structural equation model with results of studies in the context of mode choice, it is striking that PBC has a comparably small effect. Strong effects of PBC are, however, mostly found for PBC being a direct predictor of behaviour (e.g., Abrahamse et al., 2009; Haustein \& Hunecke, 2007). 
The related behaviour in our context would, however, not be departure time choice but actually arriving at work on time, which was not considered in our model.

By including the intention to arrive at work on time as determined by social norm, attitude and PBC into a DCM, we could demonstrate that accounting for the TPB significantly improved the model estimation as compared to both a basic DCM without latent variables and a model including intention estimated solely by its own indicator variables. Being restricted by the length of the questionnaire, we did not include the full set of TPB-variables for the other two intentions but only attitude towards short travel time, which we deemed most important. The selection of psychological factors was completed by perceived mobility necessities, an extension of the TPB in the context of mode choice (Haustein \& Hunecke, 2007), which we also expected to be relevant for departure time choice. As hypothesised both predictors became significant and further improved the prediction of departure time.

We additionally found that the specific effect of the different psychological variables depended on framework conditions, namely having flexible or fixed starting times at work. As expected, the intention to arrive at work on time had a stronger effect on people with fixed working hours. That the other psychological variables - PMN and ATT_Time - had a stronger effect for people with flexible time conditions can probably be explained by their better possibilities to reschedule, which allows them to be more open to the influence of other needs (or restrictions). With regard to the attitude towards short travel time, it would be interesting to learn more about what makes short travel times by car more or less attractive or important to individuals, especially to which extent this attitude is positively related to perceived mobility needs, and/or negatively related to affective motives of car use. For people who gain utility from driving, a significant reduction of their travel time is probably not a relevant motivation to reschedule their departure time, unless they perceive external pressure, e.g. in the form of high PMN. According to these considerations, attitude towards travel time and PMN may be relevant variables to collect when designing targeted measures to stimulate changes in departure time choice in an individualised marketing approach.

In the case of perceived social pressure to arrive on time (subjective norm), interventions could be targeted at company managers aiming at changing the organizational culture towards more flexible arrival times, which may decrease attitude and subjective norm towards arriving at a specific time on the individual level. These examples, which are based on the modelling results we obtained, indicate that our results have important implications at a transportation demand management level, and that other strategies consisting solely in changing travel time and cost may be effective to shift departure time demand.

Future research could also focus on the inclusion of additional psychological factors that might be relevant for departure time choice. A key question here is what makes people more or less open to rescheduling their departure time. PMN in this study can be regarded as a proxy for this, as perceived mobility demand resulting from work and family responsibilities probably determine to which extent people are actually able to reschedule. Even if they are able to reschedule, this does not necessarily imply that they are also willing to do so. Therefore, the value orientation "openness to change" might be relevant to consider in future studies. Openness to change describes how people evaluate change and variation, and challenge and excitement as guiding principles in their lives. In a two-dimensional higher order value system it is regarded as the opponent of the value "conservation" (Schwartz, 1992). To our knowledge openness to change is the only value orientation that has been found to be related to transport behaviour when socio-demographic and 
other relevant variables are controlled for. People with high openness to change are found to have more trips, longer trips and as a result higher emissions/energy use resulting from their travel (Böhler et al., 2006; Hunecke et al., 2010; Poortinga et al., 2004). People with high PMN also travel more but trips may underlie a different motivation and fall less often into the leisure category. It would be interesting to see if people with a higher openness to change are actually more open to rescheduling and to which extent their higher engagement in activities works against this.

This study represents the first attempt to fully explore the effect of latent psychological constructs as implied in the TPB, in the departure time choice. The psychological items included in the questionnaire are derived from the authors' theoretical discussions and considerations and from the application of the TPB in the field of travel mode choice (e.g. Haustein \& Hunecke, 2007). Before developing the items, it would have been very useful to have a qualitative phase including semistructured interviews followed by a more extended pre-test to obtain precise and rich information about the majority of existing beliefs and their operationalisation. This might also have resulted in higher internal consistencies of the latent variables and is thus recommended for future work in this field.

Future work is also needed to understand the policy implication of disregarding the latent psychological effects in the discrete choice. Very few works have attempted to make such forecast, concluding that the inclusion of latent psychological effects, although highly significant, does not have a major impact on forecasting. However, there is a general agreement (Yáñez et al., 2010; Raveau et al., 2010; Paulssen et al., 2014) that the gain in prediction is due to the better understanding of the cognitive process underlying the formation of individual preferences for a given alternative that is useful to the design of policies.

The sample of this study can be regarded as a possible limitation as it cannot claim representativeness for car commuters. The most relevant difference between the sample and the population of car commuters in terms of the subject of our study is probably the higher percentage of people with flexible working hours included here. As we estimated the effects of the psychological factors for people with fixed working hours and flexible working hours separately, we do not see this as a problem for the interpretation of the effects of the psychological variables. It should, however, be taken into account when interpreting the results of the scheduling model part of the model.

While the focus of our paper was on car commuters, we think that similar considerations are also relevant for commuters using public transport and, in case of cycling cities, like Copenhagen, also for cycling. To which extent our results can be transferred to commuters using other modes remains a question for future research. As public transport service quality is strongly affected by overcrowded busses and trains and perceived safety by overcrowded cycling paths, designing flexible schemes for departure times appears relevant for all types of commuters. 


\section{References}

Abrahamse, W., Steg, L., Gifford, R., \& Vlek, C. (2009). Factors influencing car use for commuting and the intention to reduce it: A question of self-interest or morality? Transportation Research Part F: Traffic Psychology and Behaviour, 12(4), 317-324. doi:10.1016/j.trf.2009.04.004

Ajzen, I. (1991). The theory of planned behavior. Organizational Behavior and Human Decision Processes, 50(2), 179-211.

Anable, J., \& Gatersleben, B. (2005). All work and no play? the role of instrumental and affective factors in work and leisure journeys by different travel modes. Transportation Research Part A: Policy and Practice, 39(2-3), 163-181. doi:10.1016/j.tra.2004.09.008

Arellana, J. (2012). Modelos de elección de la hora de inicio de viaje. (PhD dissertation, Pontificia Universidad Católica De Chile Escuela De Ingeniería).

Arellana, J., Daly, A., Hess, S., Ortúzar, J. d. D., \& Rizzi, L. I. (2012). Development of surveys for study of departure time choice two-stage approach to efficient design. Transportation Research Record, (2303), 9-18. doi:10.3141/2303-02

Armitage, C. J., \& Conner, M. (2001). Efficacy of the theory of planned behaviour: A meta-analytic review doi:10.1348/014466601164939

Bamberg, S. (2012). Understanding and promoting bicycle use - insights from psychological research. In J. Parkin (Ed.), Cycling and sustainability (pp. 219 - 246). Bingley, UK: Emerald Publishing Group Limited.

Bamberg, S., \& Schmidt, P. (1998). Changing travel-mode choice as rational choice: Results from a longitudinal intervention study. Rationality and Society, 10(2), 223-252.

Bamberg, S., \& Schmidt, P. (2001). Theory-driven subgroup-specific evaluation of an intervention to reduce private car use. Journal of Applied Social Psychology, 31(6), 1300-1329.

Bamberg, S., \& Schmidt, P. (2003). Incentives, morality, or habit? predicting students' car use for university routes with the models of ajzen, schwartz, and triandis. Environment and Behavior, 35(2), 264-285. doi:10.1177/0013916502250134

Beirao, G., \& Cabral, J. A. S. (2007). Understanding attitudes towards public transport and private car: A qualitative study. Transport Policy, 14(6), 478-489. doi:10.1016/j.tranpol.2007.04.009

Ben-Akiva, M., \& Lerman, S. R. (1985). Discrete choice analysis: Theory and application to travel demand. Cambridge, MA: MIT Press.

Ben-Akiva, M., McFadden, D., Gärling, T., Gopinath, D., Walker, J., Bolduc, D., Börsch-Supan, A., Delquié, P., Larichev, O. \& Morikawa, T. 1999, "Extended framework for modeling choice behavior", Marketing Letters, vol. 10, no. 3, pp. 187-203. 
Ben-Akiva, M., Walker, J.L., Bernadino, A.T., Gopinath, D. and Morikawa, T., 2002b, Integration of Choice and Latent Variable Models. In Perpetual Motion: Travel Behaviour Research Opportunities and Application Challenges (H.S. Majmassani ed.), Elsevier, Amsterdam, 431-470.

Bierlaire, M. (2003). BIOGEME: A free package for the estimation of discrete choice models. Proceedings of the 3rd Swiss Transportation Research Conference, Ascona, Switzerland.

Bierlaire, M., \& Fetiarison, M. (2009). Estimation of discrete choice models: Extending BIOGEME. 9th Swiss Transport Research Conference, Monte Veritá. Switzerland.

Böhler, S., Grischkat, S., Haustein, S., \& Hunecke, M. (2006). Encouraging environmentally sustainable holiday travel. Transportation Research Part A: Policy and Practice, 40(8), 652670. doi:10.1016/j.tra.2005.12.006

Börjesson, M. (2007). Departure time modelling applicability and travel time uncertainty. Proceedings of the European Transport Conference, Leiden, The Netherlands.

Börjesson, M. (2008). Joint RP/SP data in a mixed logit analysis of trip timing decisions. Transportation Research Part E: Logistics and Transportation Review, 44(6), 1025-1038.

Börjesson, M. (2009). Modelling the preference for scheduled and unexpected delays. Journal of Choice Modelling, 2(1), 29-50.

Cestac, J., Paran, F., \& Delhomme, P. (2011). Young drivers' sensation seeking, subjective norms, and perceived behavioral control and their roles in predicting speeding intention: How risktaking motivations evolve with gender and driving experience. Safety Science, 49(3), 424-432. doi:10.1016/j.ssci.2010.10.007

Cools, M., Moons, E., Janssens, B., \& Wets, G. (2009). Shifting towards environment-friendly modes: Profiling travelers using Q-methodology. Transportation, 36(4), 437-453. doi:10.1007/s11116-009-9206-Z

Ettema, D., Timmermans, H., \& Arentze, T. (2004). Modelling perception updating of travel times in the context of departure time choice under ITS. Journal of Intelligent Transportation Systems: Technology, Planning, and Operations, 8(1), 33-43.

Forward, S. E. (2009). The theory of planned behaviour: The role of descriptive norms and past behaviour in the prediction of drivers' intentions to violate. Transportation Research Part F: Traffic Psychology and Behaviour, 12(3), 198-207. doi:10.1016/j.trf.2008.12.002

Fujii, S., \& Kitamura, R. (2004). Drivers' mental representation of travel time and departure time choice in uncertain traffic network conditions. Networks and Spatial Economics, 4(3), 243-256. doi:10.1023/B:NETS.0000039781.10517.3a

Haustein, S., \& Hunecke, M. (2007). Reduced use of environmentally friendly modes of transportation caused by perceived mobility necessities: An extension of the theory of planned behavior. Journal of Applied Social Psychology, 37(8) 
Heath, Y., \& Gifford, R. (2002). Extending the theory of planned behavior: Predicting the use of public transportation. Journal of Applied Social Psychology, 32(10), 2154-2189.

Hendrickson, C., \& Planke, E. (1984). The flexibility of departure times for work trips. Transportation Research Part A: Policy and Practice, 18(1), 25-36.

Hess, S., Daly, A., Rohr, C., \& Hyman, G. (2007). On the development of time period and mode choice models for use in large scale modelling forecasting systems. Transportation Research Part A: Policy and Practice, 41(9), 802-826.

Hu, L., \& Bentler, P. M. (1999). Cutoff criteria for fit indexes in covariance structure analysis: Conventional criteria versus new alternatives. Structural Equation Modeling - A Multidisciplinary Journal, 6(1), 1-55. doi:10.1080/10705519909540118

Hunecke, M., Haustein, S., Böhler, S., \& Grischkat, S. (2010). Attitude-based target groups to reduce the ecological impact of daily mobility behavior. Environment and Behavior, 42(1), 3 43. doi:10.1177/0013916508319587

Jakobsson, C. (2007). Instrumental motives for private car use. In T. Gärling, \& L. Steg (Eds.), Threats from car traffic to the quality of urban life - problems, causes, and solutions (1st ed., pp. 205-217). Bingley, UK: Elsevier Science.

Kahneman, D. (2002) Maps of bounded rationality: a perspective on intuitive judgment and choice. Nobel Prize Lecture, Stockholm, Sweden.

Koster, P., \& Verhoef, E. T. (2012). A rank-dependent scheduling model. Journal of Transport Economics and Policy, 46(3), 123-138.

Kroes, E., Daly, A., Gunn, H., \& Van, D. H. (1996). Opening of the amsterdam ring road: A case study on short-term effects of removing a bottleneck. Transportation, 23(1), 71-82.

Lam, T. C., \& Small, K. A. (2001). The value of time and reliability: Measurement from a value pricing experiment. Transportation Research Part E: Logistics and Transportation Review, $37(2-3), 231-251$.

Levy, J. I., Von Stackelberg, K., \& Buonocore, J. J. (2010). Evaluation of the public health impacts of traffic congestion: A health risk assessment. Environmental Health: A Global Access Science Source, 9(1) doi:10.1186/1476-069X-9-65

Lizana, P., Arellana, J., Ortúzar, J. d. D., \& Rizzi, L. I. (2013). Modelling mode and time-of-day choice with joint RP and SC data. International Choice Modelling Conference (ICMC), Sydney, Australia.

Lois, D., \& Lopez-Saez, M. (2009). The relationship between instrumental, symbolic and affective factors as predictors of car use: A structural equation modeling approach. Transportation Research Part A: Policy and Practice, 43(9-10), 790-799. doi:10.1016/j.tra.2009.07.008 
McFadden, D., 2000. Disaggregate Behavioural Travel Demand's RUM Side. A 30-Year Retrospective. In: D.A. Hensher, ed. Travel Behaviour Research: The Leading Edge. Oxford: Pergamon Press

Mokhtarian, P. L., \& Salomon, I. (2001). How derived is the demand for travel? some conceptual and measurement considerations. Transportation Research Part A: Policy and Practice, $35 A(8), 695-719$.

Møller, M., \& Haustein, S. (2014). Peer influence on speeding behaviour among male drivers aged 18 and 28. Accident Analysis and Prevention, 64

Noland, R. B., \& Small, K. A. (1995). Travel-time uncertainty, departure time choice, and the cost of morning commutes. Transportation Research Record, (1493), 150-158.

Paulssen, M., Vij, A., Walker, J.L. and Temme, D., 2014, Values, attitudes and travel behavior: a hierarchical latent variable mixed logit model of travel mode choice, Transportation, 41(4), 873-888.

Poortinga, W., Steg, L., \& Vlek, C. (2004). Values, environmental concern, and environmental behavior - A study into household energy use. Environment and Behavior, 36(1), 70-93. doi:10.1177/0013916503251466

Raveau, S., Alvarez-Daziano, R., Francisca Yanez, M., Bolduc, D., \& Ortuzar, J. D. (2010). Sequential and simultaneous estimation of hybrid discrete choice models some new findings. Transportation Research Record, (2156), 131-139. doi:10.3141/2156-15

SACTRA. (1994). Trunk roads and the generation of traffic. London, United Kingdom: SACTRA (The Standing Advisory Committee on Trunk Road Assessment), The Department of Transport.

Schwartz, S. H. (1992). Universals in the content and structure of values - theoretical advances and empirical tests in 20 countries. Advances in Experimental Social Psychology, 25, 1-65.

Senbil, M., \& Kitamura, R. (2004). Reference points in commuter departure time choice: A prospect theoretic test of alternative decision frames. ITS JOURNAL, 8(1), 19-31. doi:10.1080/15472450490437726

Small, K. A. (1982). The scheduling of consumer activities: Work trips. American Economic Review, 72(3), 467-479.

Small, K. A., Noland, R. B., Chu, X., \& Lewis, D. (2000). NCHRP report 431 - valuation of traveltime savings and predictability in congested conditions for highway user-cost estimation. Washington, United States of America: Transportation Research Board, National Research Counsil, National Cooporative Highway Research Program.

Steg, L. (2005). Car use: Lust and must. instrumental, symbolic and affective motives for car use. Transportation Research Part A: Policy and Practice, 39(2-3), 147-162. doi:10.1016/j.tra.2004.07.001 
Thorhauge, M., Cherchi, E., \& Rich, J. (2014). Building efficient stated choice design for departure time choices using the scheduling model: Theoretical considerations and practical implications. Presented at Aalborg Trafikdage 2014,

Tseng, Y., Koster, P., Peer, S., Knockhaert, J., \& Verhoef, E. T. (2011). Discrete choice analysis for trip timing decisions of morning commuter: Estimations from joint SP/RP-GPS data. The Second International Choice Modelling Conference (ICMC) Proceedings, Leeds, UK.

Walker, J. L. (2001). Extended discrete choice models: Integrated framework, flexible error structures and latent variables. (PhD dissertation, Massachusetts Institute of Technology).

Walker, J. L., Ben-Akiva, M., \& Bolduc, D. (2007). Identification of parameters in normal error component logit-mixture (NECLM) models. Journal of Applied Econometrics, 22(6), 10951125. doi:10.1002/jae.971

Yanez, M. F., Raveau, S., \& Ortuzar, J. (2010). Inclusion of latent variables in mixed logit models: Modelling and forecasting. Transportation Research Part A: Policy and Practice, 44(9), 744753. doi:10.1016/j.tra.2010.07.007 